\title{
ACUTE-PHASE RESPONSE IN MONITORING POSTOPERATIVE RECOVERY IN BITCHES AFTER OVARIOHYSTERECTOMY*
}

\author{
Roman Dąbrowski`, Władysław Wawron \\ Department and Clinic of Animal Reproduction, \\ University of Life Sciences in Lublin, Głęboka 30, 20-612 Lublin, Poland \\ •Corresponding author: roman.dabrowski@up.lublin.pl
}

\begin{abstract}
An ovariohysterectomy is one of the most common procedures performed on bitches in everyday veterinary practice. As with any other surgery, it leads to a local inflammatory reaction, which is usually accompanied by a systemic reaction called the acute-phase response (APR). The aim of the study was to assess the changes of serum CRP concentration, WBC and rectal temperature during the postoperative period in bitches undergoing ovariohysterectomy and to establish the usefulness of such determinations after surgical trauma. The results showed increased levels of all the measured parameters 24 hours after surgery. During the course of a normal postoperative period, WBC count and rectal temperature return to values that are considered physiological norms for dogs. The subsequent decline in CRP during the postoperative course indicates the gradual subsidence of the inflammatory reaction to surgical trauma. CRP concentrations higher than the physiological norm noted 10 days after surgery indicate a persistent, although less severe inflammatory process. The serum concentration of CRP is a more sensitive and reliable parameter for an evaluation of the postoperative period in bitches than WBC count and rectal temperature.
\end{abstract}

Key words: bitches, ovariohysterectomy, acute-phase response, rectal temperature, WBC, CRP

Ovariohysterectomy is a commonly used method of contraception in dogs. As a surgical method in which tissue integrity is interrupted, it leads to the development of a temporary local inflammatory reaction, accompanied by a systemic reaction known as the acute-phase response (Buttenschoen et al., 2001; Mold et al., 2002). This is the reaction of tissues to infection or damage to their integrity resulting from trauma, surgery, neoplastic processes, or immune system dysfunction (Baumann and Gauldie, 1994; Buttenschoen et al., 2001; Dąbrowski et al., 2009). The acute-phase response appears quickly; its severity depends on the nature and type of stimulus. It is an element of non-specific immunity encompassing the earliest changes taking

\footnotetext{
*Work financed from statutory activity No. WKP/DS-1.
} 
place in the organism. Disturbances also occur in the metabolic profile and in the functions of the nervous and endocrine systems (Kostro et al., $2001 \mathrm{a}, \mathrm{b}$ ).

A fundamental role in the induction and modulation of the acute-phase response is played by cytokines - both pro-inflammatory (IL-1, TNF $\alpha$, IL-6, IL-8, IFN $\gamma$ ) and anti-inflammatory (including IL-4 and IL-10) (Cray, 2012). Increased production and release of these cytokines by various types of immune cells and by epithelial cells and fibroblasts occur as a consequence of their activation by factors such as stress, transport, trauma, toxins, poisoning, bacterial or viral infections, and invasion by parasites (Eckersall, 2000; Mold et al., 2002; Murata et al., 2004; Petersen et al., 2003; Póvoa et al., 1998; Póvoa, 2002).

One of the early symptoms of acute-phase response is fever (Zheng et al., 1995), which is a result of pro-inflammatory cytokines (IL-1, IL-6 and TNF- $\alpha$ ) inducing the production of prostaglandins of the E family in the anterior hypothalamus, leading to disturbances in the thermoregulatory centre. Leukocytosis and thrombocytosis are noted in the blood during acute-phase response (Baumann and Gauldie, 1994; Gogo et al., 2005; Ozaka et al., 2012; Ito et al., 2006).

During acute-phase response, changes also occur in the concentration of serum proteins known as acute-phase proteins - APP (Eckersall, 2000; Eckersall and Bell, 2010; Suffredi et al., 1999). Proteins whose concentration increases by at least $25 \%$ are called positive acute-phase proteins, while those whose concentration decreases are negative acute-phase proteins. Acute-phase proteins prevent the generalization of the inflammatory process and limit the scope of tissue damage (Eckersall and Bell, 2010). As a non-specific mechanism of innate humoral immunity, they also perform an important function in modulating the inflammatory immune response. The main sites for the production of acute-phase proteins in animals are hepatocytes, but some APP may also be synthesized by lymphocytes, monocytes, epithelial cells, and fibroblasts (Cray, 2012; Eckersall, 2000; Ulutas et al., 2009). Changes in acutephase protein concentrations in the blood reflect the severity of the inflammatory process and the extent of tissue damage (Eckersall et al., 2010). Determination of APP is of unquestionable diagnostic and prognostic value with regard to the course and outcome of the disease process (Dąbrowski et al., 2009; Eckersall et al., 2010; Kostro et al., 2001 b; Murata et al., 2004; Petersen et al., 2003; Planellas et al., 2009).

APPs in dogs can be classified by the magnitude of their response to stimuli as positive (major and moderate) or negative reactants. Haptoglobin (Hp), serum amyloid A (SAA) and C-reactive protein (CRP) are positive APPs that increase the rate of synthesis and release when an inflammation occurs and can be used in dogs as a screening test for systemic response to an inflammatory stimulus and are considered the most accurate markers of inflammation (Cerón et al., 2005; Dąbrowski et al., 2009).

The main acute-phase proteins in dogs include, among others, the C-reactive protein (CRP) (Eckersall and Bell, 2010; Shida et al., 2011; Tecles et al., 2009). This is a first-line protein whose serum concentration increases just 4-8 hours after the stimulus and reaches its maximum values after 1-2 days. It is well established that increased CRP concentrations in the blood are strongly associated with inflammation 
in dogs (Hayashi et al., 2001). Some authors (Casella et al., 2013) have shown an increase in acute-phase proteins after hunting exercise.

The effectiveness of the prevention of postoperative complications depends, to a large extent, on appropriate monitoring of the dogs' state of health. A useful method for assessing the severity of inflammatory states is the determination of acute-phase response parameters, such as C-reactive protein, white blood cell count (WBC) and rectal temperature. These parameters provide a sensitive indicator which can enable early detection of abnormalities in the postoperative period and rapid intervention to restore homeostasis in the organism, particularly in the absence of clinical disease symptoms. Hence, the aim of the study was to assess the changes of serum CRP concentration, WBC and rectal temperature during the postoperative period in bitches undergoing ovariohysterectomy and to establish the usefulness of such determinations after surgical trauma.

\section{Material and methods}

The study population was composed of 20 purebred and crossbred bitches, aged 2-4 years, with a body mass of $12-30 \mathrm{~kg}$, between the 4 th- 10 th weeks after oestrus. $30 \%$ were nulliparous and $70 \%$ primiparous, and $60 \%$ had a history of having had birth control injections with progesterone substances. Bitches were admitted to the Department and Clinic of Animal Reproduction, Faculty of Veterinary Medicine, University of Life Sciences, Lublin for elective spaying (ovariohysterectomy). Prior to the surgery, the dogs underwent clinical examination according to a gynaecological plan, as well as additional tests (haematological, biochemical, cytological, vaginoscopy, ultrasound). According to these findings, the animals were classified as healthy bitches in the anoestrus phase and selected to undergo surgical sterilization, which was performed on the next day.

Rectal temperature was measured with a veterinary electronic thermometer (Kruuse Digi-Vet SC 12) and blood was collected from the vena saphena at the following intervals: before surgery (day 0), and then 24 hours ( 1 day), 120 hours ( 5 days) and 240 hours (10 days) after the surgery. Blood samples were collected from the vena saphena into sterile VACUTEST tubes (with clot activator, $9 \mathrm{ml}$ ). Serum was obtained by centrifuging whole blood for 10 minutes $(3,000 \mathrm{rpm})$, after which it was frozen at $-76^{\circ} \mathrm{C}($ Polar $110 \mathrm{H})$ and stored until analysis (for a maximum of 4 months). Samples were free from haemolysis and lipemia.

The samples for WBC analysis were collected into sterile tubes containing EDTA (VACUTEST K3EDTA $7.2 \mathrm{mg}$ ). White blood cell count was determined using a Scil Vet abc Plus + haematology analyser (manufactured by Horiba ABX).

All samples were thawed for CRP determination on the same day.

C-reactive protein levels were determined using an immunoassay kit (PHASE ${ }^{\mathrm{TM}}$ Canine CRP Assay, ELISA, Tridelta Development Limited, Kildare, Ireland) according to the manufacturer's instructions. The absorbance of samples was measured on a microtiter plate reader (ELx800, BioTek Instruments, USA) at 
$450 \mathrm{~nm}$ using $630 \mathrm{~nm}$ as the reference. The coefficients of variation (CV) for this assay are: intra-assay $6.9 \%(15.4 \mu \mathrm{g} / \mathrm{mL})$ and $6.5 \%(35.8 \mu \mathrm{g} / \mathrm{mL})$; inter-assay $8.2 \%$ $(14.9 \mu \mathrm{g} / \mathrm{mL})$ and $7.8 \%(34.6 \mu \mathrm{g} / \mathrm{mL})$.

According to Martinez-Subiela (2003), these methods have been validated for the determination of acute-phase proteins in canine serum samples.

In accordance with the generally accepted guidelines concerning general surgery, bitches received no meal 12 hours before the planned operation (Komar, 1998). However, constant access to water was maintained. The ovariohysterectomy was performed under general anaesthesia and according to the generally accepted protocol [premedication: intramuscular xylazine (Rometar $2 \%{ }^{\circledR}-$ Spofa, Czech Republic), $2 \mathrm{mg} / \mathrm{kg}$ b.w. and atropine (Atropinum sulfuricum ${ }^{\circledR}$ - Polfa, Poland), $0.05 \mathrm{mg}$ / kg b.w.; induction: Propofol (Propofol; Pfizer, $20 \mathrm{mg} / \mathrm{ml}$ ), $2 \mathrm{mg} / \mathrm{kg}$ i.v.; maintenance: Isofluorane $1.5 \%$ in $\left.100 \% \mathrm{O}_{2}\right]$. The average duration of the ovariohysterectomy was 40 to 60 minutes, which was dependent on the dog's body weight.

The results obtained were analysed statistically; the mean, standard deviation and significance of differences were calculated. Intra-group means were compared to initial values (from before the surgery) based on variance analysis (Statistica 6.0 Software) which was conducted based on the Mann-Whitney U test. The level of significance was set at $\mathrm{P}<0.05$.

\section{Results}

After complete recovery from the operation and several hours of observation, animals were returned to their owners. Follow-up visits at the clinic were arranged to enable clinical check-ups and access to material to identify CRP and WBC.

Both during and after surgery, all bitches were given broad-spectrum antibiotics (penicillin and streptomycin - prep. Pen-Strep, Scan Vet, Poland) and polyionic fluids. Antibiotics were continued for 4 days in dogs after ovariohysterecromy.

The first day after surgery, bitches demonstrated normal behaviour towards environmental stimuli and they drank water; however, the bitches did not accept food. The frequency and the amount of urine was normal. The second day after surgery, $90 \%$ of bitches started accepting food in a liquid form. In the following days, the appetite and thirst came to normal in all bitches. The 10th day after surgery, sutures were removed and continuity of tissues was checked properly. Postoperative wounds healed through per primam intentionem.

The results of the rectal temperature measurements over the course of the experiment are presented in Figure 1. The data show that before the procedure the average rectal temperature was $38.3^{\circ} \mathrm{C}( \pm 0.5)$. On the first day after the surgery, this rose to an average of $39.1^{\circ} \mathrm{C}( \pm 0.3)$ - a statistically significant increase compared to the pre-surgery temperature $(\mathrm{P} \leq 0.05)$. On subsequent testing days, internal body temperature was within physiological norms for dogs and no statistically significant differences were noted. 
Haematological findings are presented in Table 1.

The white blood cell counts in the dogs' blood are presented in Figure 2. The average WBC count before the procedure was $9.6( \pm 1.6) \times 10^{9} / 1$, while on the first day after the ovariohysterectomy the leukocyte count increased significantly, reaching a value of $18.8( \pm 2.5) \times 10^{9} / 1$ (a statistically significant difference at $\mathrm{P} \leq 0.05$ compared to the initial value). On subsequent testing days, the average leukocyte count decreased compared to its maximum value, reaching a value of $11.2( \pm 4.1) \times 10^{9} / 1$ on the tenth day after the ovariohysterectomy. The final mean leukocyte count was within the physiological norm for dogs.

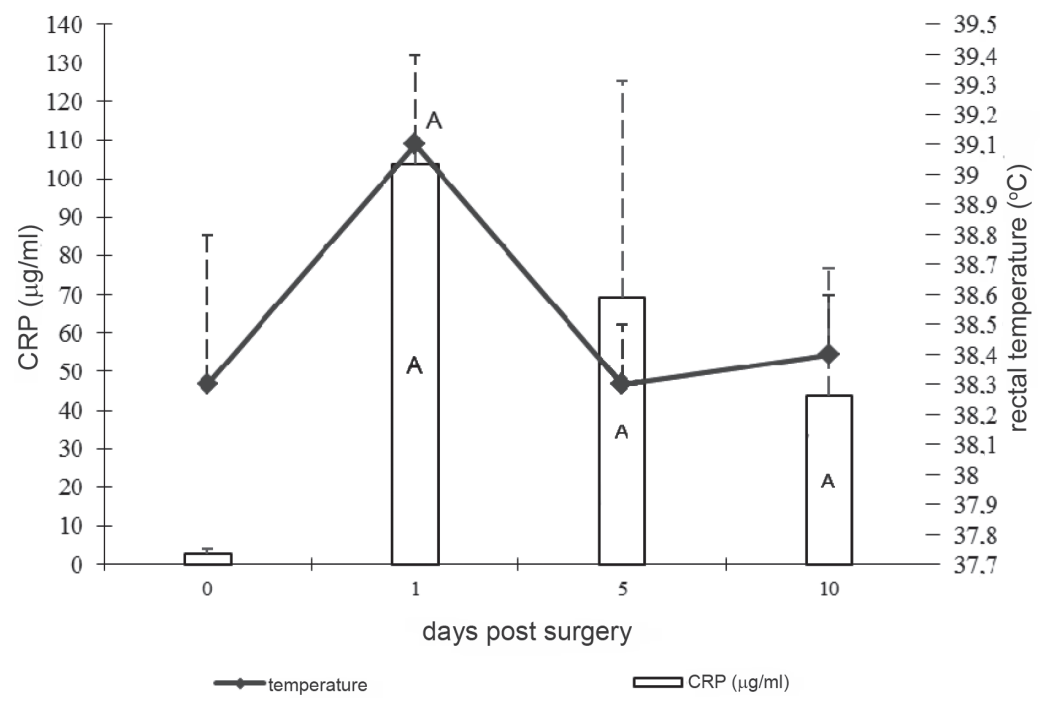

Figure 1. Serum C-reactive protein $(\mathrm{CRP})$ concentrations $(\mu \mathrm{g} / \mathrm{ml})$ and rectal temperature $\left({ }^{\circ} \mathrm{C}\right)$ in bitches throughout the experiment

A - statistically significant differences compared to the initial value $(\mathrm{P} \leq 0.05)$

Table 1. Selected haematological parameters determined in the blood of bitches throughout the experiment: number of erythrocytes $\times 1012 / 1, \mathrm{Hb}(\mathrm{g} / \mathrm{l})$ and $\mathrm{Ht}(\%)$

\begin{tabular}{l|c|c|c|c}
\hline \multirow{2}{*}{\multicolumn{1}{c}{ Item }} & \multicolumn{4}{c}{ Time intervals of study } \\
\cline { 2 - 5 } & $\begin{array}{c}0 \\
\text { before surgery }\end{array}$ & $\begin{array}{c}24 \mathrm{~h} \\
\text { after surgery }\end{array}$ & $\begin{array}{c}5 \mathrm{~d} \\
\text { after surgery }\end{array}$ & $\begin{array}{c}10 \mathrm{~d} \\
\text { after surgery }\end{array}$ \\
\hline Number of erythrocytes in the blood & 6.4 & 6.1 & 5.9 & 5.8 \\
$\times 10^{12} / 1$ & $( \pm 0.6)$ & $( \pm 0.5)$ & $( \pm 0.8)$ & $( \pm 0.9)$ \\
Level of haemoglobin in the blood $(\mathrm{g} / \mathrm{l})$ & 14.1 & 13.8 & 13.3 & 13.1 \\
& $( \pm 1.7)$ & $( \pm 1.2)$ & $( \pm 1.8)$ & $( \pm 2.2)$ \\
Level of haematocrit in the blood $(\%)$ & 44.6 & 42.9 & 40.5 & 39.3 \\
& $( \pm 4.3)$ & $( \pm 3.7)$ & $( \pm 5.7)$ & $( \pm 5.9)$ \\
\hline
\end{tabular}




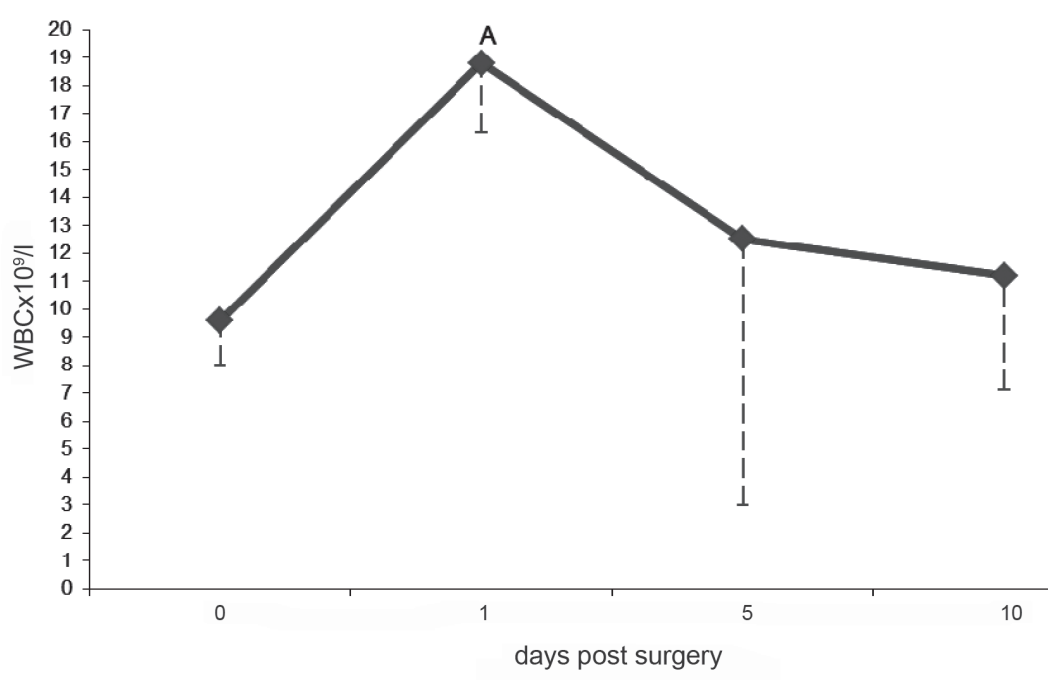

Figure 2. White blood cell (WBC) count in bitches throughout the experiment $\left(\times 10^{9} / 1\right)$ A - statistically significant differences compared to the initial value $(\mathrm{P} \leq 0.05)$

The changes in the level of C-reactive protein in the blood over the course of the experiment are presented in Figure 1. Before the surgery, the average CRP level was $2.8( \pm 1.1) \mu \mathrm{g} / \mathrm{ml}$. On the first day after the surgery, there was a statistically significant increase in CRP level, which rose to a value of $103.8( \pm 65.2)$ $\mu \mathrm{g} / \mathrm{ml}(\mathrm{P} \leq 0.05)$; this proved to be the maximum value for the entire experiment. On the fifth day after the surgical procedure, a decrease in C-reactive protein concentration was noted compared to the first day after the surgery $(69.4 \pm 55.8 \mu \mathrm{g} / \mathrm{ml})$; however, compared to the value from before the surgery, it remained at a statistically higher level. On day 10 after the surgery, the average CRP concentration was 43.9 $( \pm 32.9) \mu \mathrm{g} / \mathrm{ml}(\mathrm{P}<0.05)$.

\section{Discussion}

One of the early symptoms of the acute-phase response is fever (Zheng et al., 1995), which is the result of pro-inflammatory cytokines (IL-1, IL-6 and TNF- $\alpha$ ) acting on the thermoregulatory centre in the hypothalamus. However, there is not always a positive correlation between increased internal body temperature and the severity of inflammatory processes. This was confirmed by the present study, in which the internal body temperature in the dogs undergoing surgical sterilization remained within the physiological norm for dogs throughout the experiment, except for the first day of observation. The statistically significant increase in rectal temperature compared to its value before the surgery may have resulted from activation of the acute-phase response due to the ovariohysterectomy. However, a comparison of the overall dynamics of the changes in the concentrations of CRP and rectal tempera- 
ture on all testing days (Figure 1) indicates that acute-phase protein determination is a more sensitive and reliable parameter for use in evaluating the postoperative period in bitches. This is confirmed by results obtained by other authors, which have shown that CRP serum concentration remaining at a high level was positively correlated with a decline in patients' overall state of health, while rectal temperature remained close to the physiological norm (Póvoa, 2002).

Another indicator of the acute-phase response is leukocytosis. In the present study, a significant increase was noted in mean leukocyte count in comparison with the initial values on the first day after the ovariohysterectomy. This may be due to activation of a systemic acute-phase response resulting from an interruption of tissue integrity and the development of a local inflammatory reaction (Ho et al., 2001). A similar increase in WBC count was observed by Yamamoto et al. (1993) following surgical removal of the uterus and ovaries in dogs, as well as by Mattila-Vuori et al. (2000) after inguinal hernia surgery in children. In the present study, a gradual decrease in the total number of leukocytes was observed on day 5 after the ovariohysterectomy, and on the last day of testing their average values were within the physiological norm for dogs. This was accompanied by a normalization of the CRP serum concentration. This indicates that the inflammatory process induced by the surgical procedure was ending and that the course of the postoperative period in the dogs was normal.

During the acute-phase response, changes occur in the concentration of the serum proteins known as acute-phase proteins. This was confirmed by the results of the present study, in which the mean CRP values were within physiological norms for dogs prior to the ovariohysterectomy. The immediate increase in CRP concentrations and their maximum concentration on the first day after the ovariohysterectomy indicate that these proteins respond rapidly in dogs and are induced by the same mechanisms (Baumann and Gauldie, 1994; Ulutas et al., 2009). This increase in CRP may be the consequence of enhanced production of pro-inflammatory cytokines, which are the main signal inducing the transcription factors of genes responsible for changes in the biosynthesis of CRP in hepatocytes resulting from interruption of tissue integrity and the development of a local inflammatory reaction induced by surgery (Murata et al., 2004; Petersen et al., 2003). The decreasing CRP concentrations on subsequent testing days indicate that the inflammatory reaction induced by the surgery was ending. Similar results were obtained by Serin-Ulutas (2010) and Siracusa et al. (2008), who assayed acute-phase proteins in bitches undergoing surgical sterilization, and by Kajikawa et al. (1999), who observed decreasing CRP concentrations in cats following urinary system surgery. However, CRP concentrations in the serum of the dogs on the last day (day 10) of the experiment remained elevated compared to physiological norms, which indicates that a weak inflammatory process was still active. On this testing day, no clinical symptoms were to be observed in consequence of the surgery. Some authors (Georgieva et al., 2013) have shown that serum CRP may be considered an early positive acute-phase protein and may be used as a helpful indicator for an early diagnosis of staphylococcal infection in dogs.

In conclusion, the results of the present study demonstrate that ovariohysterectomy as a surgical method leads to the development of a local inflammatory re- 
action and activation of the acute-phase response. This is manifested as early as 24 hours after the stimulus as an increase in some parameters of the APR: concentrations of C-reactive protein, leucocytosis and rectal temperature. During the course of a normal postoperative period, WBC and rectal temperature return to values that are considered physiological norms for dogs. The subsequent decline in CRP during the postoperative course indicates the gradual subsidence of the inflammatory reaction to surgical trauma. CRP serum concentration is a more sensitive and reliable parameter for evaluating the postoperative period in bitches than WBC count and rectal temperature. The introduction of CRP to routine veterinary diagnostic determinations extends the capabilities of the monitoring of inflammatory processes and provides direction for future studies designed to provide better information to improve postoperative recovery in bitches.

\section{References}

B a u m a n n H., G a u l d i e J. (1994). The acute phase response. Immunol. Today, 15: 74-80.

Buttenschoen K., Buttenschoen D.C., B erger D., Vasilescu C., Schafheutle S., Go elt e n both B., S e idel mann M. (2001). Endotoxemia and acute-phase proteins in major abdominal surgery. Am. J. Surg., 181: 36-43.

Casella S., Fazio F., Russo C., Giudice E., Piccione G. (2013). Acute phase proteins response in hunting dogs. J. Vet. Diagn. Invest., 25: 577-580.

C e rón J.J., E a ckers all P.D., M a r t in e z-S u bie la S. (2005). Acute phase proteins in dogs and cats; current knowledge and future perspectives. Vet. Clin. Path., 34: 85-99.

Cr a y C. (2012). Acute phase proteins in animals. Prog. Mol. Biol. Transl., 105: 113-150.

Dąbrowski R., Kostro K., Lis i e cka U., S z c zubiał M., Krakowski L. (2009). Usefulness of C-reactive protein, serum amyloid A component, and haptoglobin determinations in bitches with pyometra for monitoring early post-ovariohysterectomy complications. Theriogenology, 72 : 471-479.

E ckers all P.D. (2000). Recent advances and future prospects for the use of acute phase proteins as markers of disease in animals. Rev. de Medicina Veterinaria, 151: 577-584.

E c k e r s a 11 P.D., B e 11 R. (2010). Acute phase proteins: Biomarkers of infection and inflammation in veterinary medicine. Vet. J., 185: 23-27.

G e or g i e va T.M., Z a pry a n o va D., N i k i for o I., D e n e v S.A. (2013). Plasma C-reactive protein concentration in dogs with experimentally-induced Staphylococcus aureus infection. Rev. Méd. Vét., 164: 156-161.

G og o P.B., S chne id e r D.J., Ter r i e n E.F., Wa tk in s M.W., S ob el B.E., D a u e r m a n H.L. (2005). Relation of leukocytosis to C-reactive protein and interleukin-6 among patients undergoing percutaneous coronary intervention. Am. J. Cardiol., 96: 538-542.

Hay a sh i S., Jinbo T., Iguch i K., Shimizu M., Shimada T., Nomura M., Ishida Y., Y a m a m o to S. (2001). A comparison of the concentrations of C-reactive protein and alphal-acid glycoprotein in the serum of young and adult dogs with acute inflammation. Vet. Res. Commun., 25: 117-126.

Ho Ch.S.K, Ló pe z J.A., Vu ck k vi c S., P y k e Ch.M., Ho c ke y R.L., H art D.N.J. (2001). Surgical and physical stress increases circulating blood dendritic cell counts independently of monocyte counts. Blood, 98: 140-145.

It o K., A sano T., Yoshii H., S a toh A., S um it o mo M., Hay a kaw a M. (2006). Impact of thrombocytosis and C-reactive protein elevation on the prognosis for patients with renal cell carcinoma. Int. J. Urol., 13: 1365-1370.

Kajikawa T., Furuta A., On ish i T., Taj i ma T., S ug i i S. (1999). Changes in concentrations of serum amyloid A protein, $\alpha 1$-acid glycoprotein, haptaglobin, and C-reactive protein in feline sera due to induced inflammation and surgery. Vet. Immunol. Immunop., 68: 91-98. 
K o m a r E. (1998). Anaesthesia of domestic and laboratory animals (in Polish), p. 17.

Kostro K., G liński Z., Woj c i cka-L orenow ic z K., Krakow ski L. (2001 a). Diagnostic usefulness of determining acute phase proteins in dogs and cats (in Polish). Mag. Wet., 10: 42-44.

Kostro K., Gliński Z., Wój cicka-Lorenowicz K., Krakowski K. (2001 b). Acutephase proteins as indicators of diseases in animals. Med. Weter., 57: 539-542.

Martinez-Subiela S., Tecles F., Parra M.D., Ceron J.J. (2003). Analytical validation of different methods for determination of main acute phase proteins in canine serum samples. Proc. 4 th European Colloquium on Acute Phase Protein, 25-26.09.2003, Segovia, Spain, p. 142.

Mattila-Vu ori A., S a lo M., I is a lo E., P a ju lo O., Vilj a n t o J. (2000). Local and systemic immune response to surgery under balanced anaesthesia in children. Pediatr. Anesth., 10: 381-388.

Mold C., Rodriguez W., Rodic-Polic B., Du Clos T.W. (2002). C-reactive protein mediates protection from lipopolysaccharide through interactions with Fc $\gamma$ R. J. Immunol., 169: 7019-7025.

Murata H., Shimada N., Yoshioka M. (2004). Current research on acute phase proteins in veterinary diagnosis: an overview. Vet. J., 168: 28-40.

O z a k a M., I s h i i H., Yuk is a w a S. (2012). High C-reactive protein (CRP) level and leukocytosis as a prognostic factor for metastatic pancreatic cancer (MPC) patients with good performance status. American Society Clinical Oncology, J. Clin. Oncol., 30, (Suppl.; Abstr. no. e14677).

Petersen L.H., A a lba ek B., Rontved C.M., Ing varts en K.L., S orens en N.S., He e g a a r d P.M., J e n s e n H.E. (2003). Early pathogenesis and inflammatory response in experimental bovine mastitis due to Streptococcus uberis. J. Comparat. Pathol., 128: 156-164.

Planellas M., Bassols A., Siracusa C., Saco C., Giménez M., Pato R., Pastor J. (2009). Evaluation of serum haptoglobin and C-reactive protein in dogs with mammary tumors. Vet. Clin. Pathol., 38: 348-352.

Póvo a P., A 1 me id a E., Moreira P., Fernandes A., Mealha R., Aragao A., S abino H. (1998). C-reactive protein as an indicator of sepsis. Intensive Care Medicine, 24: 1052-1056.

P ó v o a P. (2002). C-reactive protein: a valuable marker of sepsis. Intens. Care Med., 28: 235-243.

S e r in G., U l u t a s P.A. (2010). Measurement of serum acute phase proteins to monitor postoperative recovery in anoestrous bitches after ovariohysterectomy. Vet. Rec., 166: 20-22.

Shida T., Kuribayashi T., Seita T., Maruo T., Yamamoto S. (2011). Characteristic of C-reactive protein (CRP), $\alpha 1$-acid glycoprotein (AAG) and serum amyloid A (SAA) in dogs and cats with malignant cancer. J. Appl. Res. Vet. Med., 9: 376-381.

Siracusa C., Manteca X., Cerón J., Martínez-Subiela S., Cuenca R., Lavín S., G a r c i a F., P a s t o r J. (2008). Perioperative stress response in dogs undergoing elective surgery: variations in behavioural, neuroendocrine, immune and acute phase responses. Anim. Welfare, 15: $259-273$.

Suffredi A.F., Fantuzzi G., B a d o l a t o R., O p pen he i m J.J., O ' Gra d y N.P. (1999). New insights into the biology of the acute phase response. J. Clin. Immunol., 19: 203-214.

Tecles F., Tecles F., Caldín M., Zanella A., Membiela F., Tvarijonaviciute A., S u b i e la S.M., C e r ó n J.J. (2009). Serum acute phase protein concentrations in female dogs with mammary tumors. J. Vet. Diagn. Invest., 21: 214-219.

U lut a s P.A., M u s a 1 B., K ir a 1 F., B i 1 d i k A. (2009). Acute phase protein levels in pregnancy and oestrus cycle in bitches. Res. Vet. Sci., 86: 373-376.

Yamamoto S., Shida T., Miyaji S., Santsuka H., Fujis e H., Mukawa K., Furukaw a E., Naga e T., Naiki M. (1993). Changes in serum C-reactive protein levels in dogs with various disorders and surgical trauma. Vet. Res. Commun., 17: 85-93.

Zheng H., Fletcher D., Kozak W., Jiang M., Hofmann K.J., Corn C.A., S oszyńs ki D., Grabie c Ch., Trumbauer M.E., Shaw A., Kostura M.J., Steven s K., Ros en H., Ros en H., North R.J., Chen H.Y., Toc ci M.J., Kluger M.J., Van der Ploeg L.H.T. (1995). Resistance to fever induction and impaired acute-phase response in interleukin-1 $\beta$ deficient mice. Immunity, 3: 9-19.

Received: 20 IX 2013

Accepted: 27 I 2014 